\title{
Study of Thermal Characteristics Augmentation of the Aluminium Oxide Nano Fluid with Different Base Fluids
}

\author{
Rokkala Rudrabhiramu $^{1,2^{*}}$, Kiran Kumar Kupireddi ${ }^{3}$, Kuchibotla Mallikarjuna Rao ${ }^{2}$ \\ ${ }^{1}$ Department of Mechanical Engineering, Vignan's Institute of Information Technology, Visakhapatnam 530049, AP, India \\ ${ }^{2}$ Department of Mechanical Engineering, Jawaharlal Nehru Technological University, Kakinada 533003, AP, India \\ ${ }^{3}$ Department of Mechanical Engineering, National Institute of Technology, Warangal, Telangana 506004, India
}

Corresponding Author Email: rokkalarudrabhiramu@gmail.com

https://doi.org/10.18280/ijht.390639

Received: 2 November 2021

Accepted: 27 December 2021

\section{Keywords:}

heat transfer augmentation, aluminium oxide nano fluid, ethylene glycol, square cavity, finite element model, CFD study, square element mesh grid, isothermal wall

\begin{abstract}
Nanofluids have been widely studied over the past decade due to their extremely promising findings in terms of thermal transfer improvement techniques. These fluids have a number of potential benefits, including enhanced thermal resistance and heat transfer characteristics. The current study examines the numerical behavior of the square cavity loaded with a nanofluid for thermal enhancement under three different base fluid conditions (water, water-EG mixture, and EG). This square cavity edge is maintained at a length of $8 \mathrm{~cm}$. Side edges are kept at constant high and low-temperature conditions, and bottom sides are insulated. Additionally, it is found that when the base fluid's composition changes between EG to water, heat transmission is increased. The ( $h n f h b f /$ ) ratio improves when the percent vol density of $\mathrm{Al}_{2} \mathrm{O}_{3}$ nanoparticle increases, and an increase of up to 4.5 percent is possible. Consequently, the paper concluded that the use of nanofluids aids in heat transfer enhancement.
\end{abstract}

\section{INTRODUCTION}

Nanofluids are binary mixtures of a base fluid with metallic particles (10 nm - $100 \mathrm{~nm}$ in size). The inclusion of nano-sized metal particles colloquially referred to as nanoparticles have been found to enhance the thermal of the fluid, thus increasing the heat transfer phenomena. However, the degree to which nanoparticles absorb heat may be dependent on their volume concentration. Nanoparticles may improve heat transmission up to a specific point in their volume concentration range and may reduce it beyond that point. This range of optimum nanoparticle volume concentration levels may also be dependent on the concentration of the base fluid and the source's temperature. In aggregate, it becomes a highly complicated issue, and more research is necessary to fully comprehend this phenomenon.

Several significant research has been conducted before to better understand the improvement of heat transfer through nanofluids [1, 2]. Kamyar et al. [3] used the lattice Boltzmann method to compare a numerical model to experimental data for a nanofluid system. They demonstrated that numerical methods were in close accord with experimental findings. They suggested that rather than modeling the nanofluid as either a single-phase system, a two-phase system is more appropriate. Additionally, they recommended that numerical modeling of nanofluids should include temperature-dependent thermophysical characteristics.

$\mathrm{Li}$ and Peterson [4] studied the buoyancy-based convection in an aluminium oxide nano fluid. Effect of nanoconcentration was analysed for 0.5 to $6 \%$. They inferred that with the advance in volume concentration, the heat transmission decreased. They ascribed this degradation to the nanofluid's increased viscosity and the occurrence of
Brownian motion. They hypothesized that perhaps the thermophoresis impact delayed the start of natural convection. The findings of this study contradicted earlier findings.

Dagtekin and Oztop [5] investigated the impact of 2 different thermal partitions, their size, and placement inside an enclosure on natural circulation phenomena. Hwang et al. [6] examined a rectangular cavity and performed a buoyancydriven heat transfer study of water-based $\left(\mathrm{Al}_{2} \mathrm{O}_{3}\right)$ nanofluids. The ratio of the heat transfer coefficients of nanofluids to the base fluid falls as the size of the nanoparticles rises. Putra et al. [7] conducted heat transfer tests on a cylindrical device having a bottom and top thermal temperature and nanofluid. There was no indication of stratification of concentration layers. However, there was a reduction in spontaneous convective heat transmission. This decrease was attributable to the nanoparticles' concentration and the cylinder's aspect ratio. Goktepe et al. [8] compared single-phase and two-phase models for nanofluid convection at the entrance of an evenly heated tube. Numerous experts have done further study in nanofluids [9, 10]. Nguyen et al. [11] investigated the impact of nanoparticle size on a water aluminum oxide nanofluid. They tested the viscosity of two distinct particle sizes at various temperatures experimentally. Yazdi et al. [12] investigated the impact of Brownian motion upon this temperature increase of a nanofluid in a cavity. They examined Brownian motion's impact on a hollow loaded with water and $\mathrm{Al}_{2} \mathrm{O}_{3}$ nanoparticles. Buongiorno [13], Pak and Cho [14] investigated the impact of the nanofluid in a circular tube on oxide dual metallic nano atoms of alumina $\left(\mathrm{Al}_{2} \mathrm{O}_{3}\right) \&$ titanium oxide $\left(\mathrm{TiO}_{2}\right)$. They studied the heat transport behavior of a circular pipe and calculated the turbulent friction. Finally, Ahadi et al. [15] investigated the Soret effect's impact on the heat transmission of nanofluids. 
In earlier research, the heat enhancement phenomena in nanofluids were analyzed using a comparison of pure water and pure Ethylene glycol as a primary fluid. Several pieces of research have also examined the heat enhancement capabilities of a combination of water and ethylene glycol in different quantities. However, no study discusses the variation in heat transfer behavior caused by the progressive transition from distilled water to a water-Ethylene glycol combination to a $100 \%$ Ethylene glycol mixture. The current article presents a numerical model like any $8 \mathrm{~cm}$ square enclosing loaded by $\mathrm{Al}_{2} \mathrm{O}_{3}$ nanofluid. The present study is unique in that it investigates and reports on the impact of progressive changes in the mixture of the different composite fluids.

\section{FINITE ELEMENT MODEL}

A two-dimensional square cavity filled with nanofluid and measuring $8 \mathrm{~cm}$ in length is examined to determine the impact of heat transmission (or heat removal). The cavity's upper and bottom walls are insulated, while its lateral sides are isothermal. The current research analyses a nanofluid composed of the base fluid and aluminium oxide $\left(\mathrm{Al}_{2} \mathrm{O}_{3}\right)$ particles at concentrations ranging from Approximately $1 \%-$ $3 \%$ (volume percent concentration). The nanofluid is evaluated for three distinct base liquids: water, ethylene glycol (EG), and water-EG, as well as at four different hot wall temperature levels: $306 \mathrm{~K}, 312 \mathrm{~K}, 318 \mathrm{~K}$, and $324 \mathrm{~K}$.

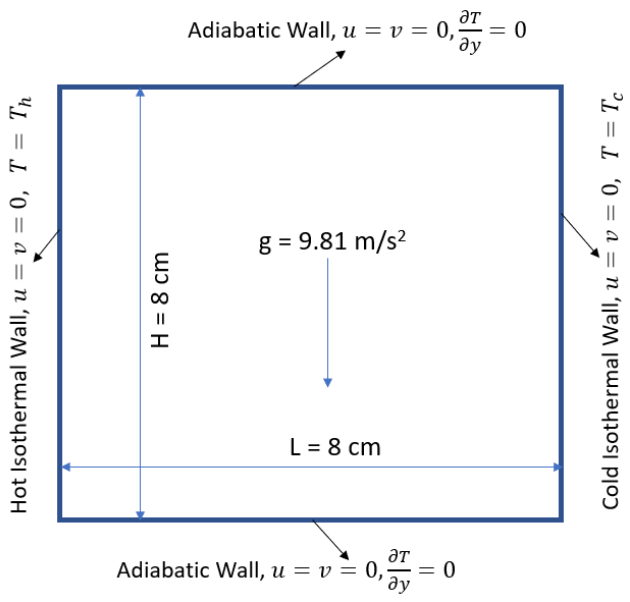

Figure 1. Model information with bounded values

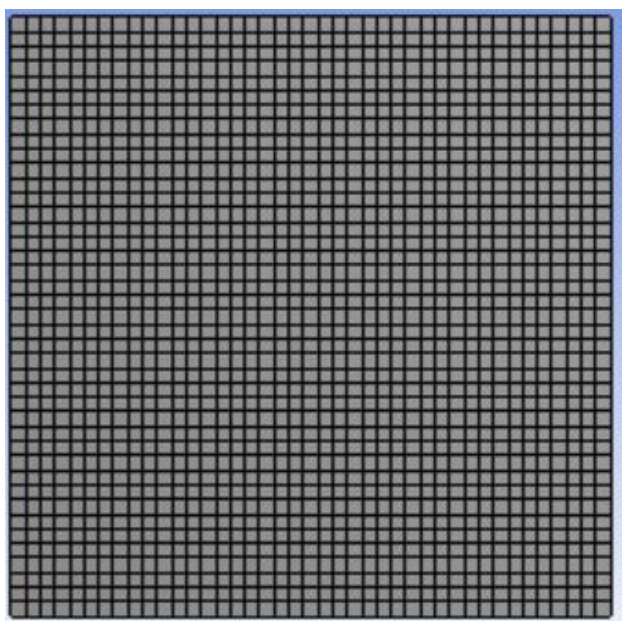

Figure 2. Discretised model
A cavity having boundary conditions is shown in Figure 1, which displays a square cavity. The governing equations are simulated using the finite element method. The baseline fluid and nanoparticle combination are considered to be homogeneous and to act as a single system. Figure 1 depicts the direction of that same gravitational vector utilized in the simulation model. The gravity vector includes the buoyancy effect caused by lateral wall heating. It is shown in Figure 2 that the study was done using a square-element mesh grid.

\section{NUMERICAL ANALYSIS}

The current study assumes that the flow is incompressible. Assuming that the nano-particles are readily humidified in the base fluid, the nanofluid is regarded as a single system. The primary objective of this study is to explore the temperature enhancement (or rate of heat transmission) and circulation behaviour of nano-fluids. Henceforth, any impact caused by an external force (for example, a magnetic field) is ignored. The model's boundary conditions are depicted in Figure 1 and are as follows:

$$
\begin{gathered}
u=v=0, T=T_{h} \\
u=v=0, T=T_{c} \\
u=v=0, \frac{\partial T}{\partial y}=0
\end{gathered}
$$

$$
\begin{gathered}
\text { at } x=0, \& 0 \leq y \leq 8 \\
\text { at } x=8, \& 0 \leq y \leq 8 \\
\text { at } y=0,8 \& 0 \leq x \leq 8
\end{gathered}
$$

(All values in $\mathrm{cm}$ )

(The origin is assumed to be at the cavity's south-west corner.)

Based on experimental observations, Khanafer et al. [16] have assessed and suggested the following values for the following characteristics of nanofluids: mass density $\left(\rho_{\text {nano fluid }}\right)$, Absolute viscosity $\left(\mu_{\text {nano fluid }}\right)$, thermal conductivity ( $k_{\text {nano fluid }}$ ), thermal expansion coefficient ( $\left.\beta_{\text {nano fluid }}\right)$, and specific heat capacity $\left(C_{p_{\text {nano fluid }}}\right)$. The values for these properties are shown below:

Mass Density, ( $\left.\rho_{\text {nano fluid }}\right)$ :

$$
\rho_{\text {nano fluid }}=\varphi \rho_{n p}+(1-\varphi) \rho_{\text {base fluid }}
$$

Absolute Viscosity, $\left(\mu_{\text {nano fluid }}\right)$ :

$$
\mu_{\text {nano fluid }}=\frac{\mu_{\text {base fluid }}}{(1-\varphi)^{2.5}}
$$

Thermal conductivity, $\left(k_{\text {nano fluid }}\right)$ :

$$
\begin{aligned}
& \frac{k_{n a n o ~ f l u i d}}{k_{\text {base fluid }}} \\
& =\frac{k_{n p}+2 k_{\text {base fluid }}+2\left(k_{n p}-k_{\text {base f } ; \text { uid }}\right) \varphi}{k_{n p}+2 k_{\text {base fluid }}-2\left(k_{n p}-k_{\text {base fluid }}\right) \varphi}
\end{aligned}
$$

Thermal volume expansion, $\left(\beta_{n f}\right)$ :

$$
\begin{aligned}
(\rho \beta)_{\text {nano fluid }}= & \varphi \rho_{n p} \beta_{n p} \\
& +(1-\varphi) \rho_{\text {base fluid }} \beta_{\text {base fluid }}
\end{aligned}
$$

Specific heat capacity, $\left(C_{p_{\text {nano fluid }}}\right)$ :

$$
\begin{aligned}
\left(\rho c_{p}\right)_{\text {nano fluid }}= & \varphi \rho_{n p} c_{p_{n p}} \\
& +(1-\varphi) \rho_{\text {base fluid }} c_{p_{\text {base fluid }}}
\end{aligned}
$$


Table 1. Properties of the base solution and $\mathrm{Al}_{2} \mathrm{O}_{3}$

\begin{tabular}{cccccccc}
\hline \multirow{2}{*}{ Property } & \multirow{2}{*}{ Water } & $\begin{array}{c}\mathbf{0 . 8 : 0 . 2} \\
\text { W/EG }\end{array}$ & $\begin{array}{c}\mathbf{0 . 6 : 0 . 4} \\
\text { W/EG }\end{array}$ & $\begin{array}{c}\mathbf{0 . 4 : 0 . 6} \\
\text { W/EG }\end{array}$ & $\begin{array}{c}\mathbf{0 . 2 : 0 . 8} \\
\text { W/EG }\end{array}$ & Ethylene-Glycol & Aluminium Oxide $\left(\mathbf{A l}_{\mathbf{2}} \mathbf{O}_{3}\right)$ \\
\hline$\rho$ & 988 & 1018.549 & 1047.948 & 1073.978 & 1097.293 & 1121.669 & 3933.767927 \\
$c_{p}$ & 4211 & 3854.375 & 3510.846 & 3129.035 & 2709.95 & 2366.421 & 770.673445 \\
$k$ & 0.702 & 0.570303 & 0.467237 & 0.384783 & 0.324088 & 0.295458 & 45.80750408 \\
$\mu$ & 0.877 & 1.437059 & 2.529618 & 4.448979 & 8.159742 & 14.86274 & - \\
$\alpha \times 10^{7}$ & 1.5 & 1.291837 & 1.128571 & 1.018367 & 0.969388 & 0.989796 & 134.3877551 \\
$\beta$ & 0.00019 & 0.000253 & 0.000317 & 0.00038 & 0.000443 & 0.000516 & 0.0000217 \\
$P r$ & 5.99 & 11.06226 & 21.66071 & 41.22936 & 77.75158 & 135.6681 & - \\
\hline
\end{tabular}

Three different baseline liquids (Water, Ethylene glycol (EG), and Water-EG) are examined and compared in this study at varied $\mathrm{Al}_{2} \mathrm{O}_{3}$ nanoparticle concentrations $(=1 \%, 2 \%$, and $3 \%)$. The water-EG combination is tested at with varying compositions: $\quad 0.2-0.8, \quad 0.4-0.6, \quad 0.6-0.4$, and $0.8-0.2$ concentrations. The thermal fluid characteristics of common basic fluids are shown in Table 1. The low temperature side is maintained at $300 \mathrm{~K}$, while the temperature of the heated isothermal wall is studied at three different temperature levels are $306 \mathrm{~K}, 312 \mathrm{~K}, 318 \mathrm{~K}, \& 324 \mathrm{~K}$. As a result, three factors are examined (one at a time): (a) the percent volume concentration of $\mathrm{Al}_{2} \mathrm{O}_{3}$ nanoparticles; (b) the composition of the base fluid; and (c) the temperature. Table 1 shows the properties of the base solution and $\mathrm{Al}_{2} \mathrm{O}_{3}$ nanoparticles concerning each other.

The density value is estimated numerically using the Boussinesq approximation since its value varies proportionally with temperature in the momentum equation's buoyancy component. During the numerical simulation, the other characteristics are considered to stay constant. With the above in mind, the incompressible flow's dominant continuity, momentum, as well as energy equations are as follows:

Continuity Equation:

$$
\frac{\partial u}{\partial x}+\frac{\partial v}{\partial y}=0
$$

Momentum Equation:

$$
\begin{gathered}
u \frac{\partial u}{\partial x}+v \frac{\partial u}{\partial y}=\frac{1}{\rho_{n f}}\left[-\frac{\partial P}{\partial x}+\mu_{n f}\left(\frac{\partial^{2} u}{\partial x^{2}}+\frac{\partial^{2} u}{\partial y^{2}}\right)\right] \\
u \frac{\partial v}{\partial x}+v \frac{\partial v}{\partial y}=\frac{1}{\rho_{n f}}\left[-\frac{\partial P}{\partial y}+\mu_{n f}\left(\frac{\partial^{2} v}{\partial x^{2}}+\frac{\partial^{2} v}{\partial y^{2}}\right)\right] \\
+\left\{g(\rho \beta)_{n f}\left(T-T_{c}\right)\right\}
\end{gathered}
$$

Energy Equation:

$$
u \frac{\partial T}{\partial x}+v \frac{\partial T}{\partial y}=\alpha_{n f}\left(\frac{\partial^{2} T}{\partial x^{2}}+\frac{\partial^{2} T}{\partial y^{2}}\right)
$$

\section{SOLUTION PROCEDURE}

CFD study of the square cavity's free convection issue is carried out using Fluent 16.0 software. A simple method is used with default relaxation factor settings. All the residuals of the governing equations are fixed at $10^{-6}$.

The mesh sensitivity study using $\mathrm{Al}_{2} \mathrm{O}_{3}$-water nanofluids with $=3 \%$ and $T=T_{h}-T_{c}=12 \mathrm{~K}$ are shown in Table 2 . To perform a grid independence test, we used a hexagonal mesh grid (Figures 3 and 4). According to the findings, the numerical analysis may be conducted effectively using a 14400-squareelement mesh grid.

Two studies utilize square cavities of $8 \mathrm{~cm}$ length loaded with $\mathrm{Al}_{2} \mathrm{O}_{3}$-water nanofluid for data validation: Ho et al. The cavity's vertical walls are isothermal, whereas the cavity's horizontal walls are adiabatically heated. The temperatures of both the warm and cool isothermal walls are kept around 312 $\mathrm{K} \& 300 \mathrm{~K}$, respectfully. Table 3 summarises the predicted results in comparison with the obtained results. As the nanoparticle concentration rises, the variance increases from 2.31 to 4.34 percent, but this difference is within acceptable limits, and therefore the technique used in the present numerical study is deemed verified.

Table 2. Grid independence study

\begin{tabular}{cccc}
\hline $\begin{array}{c}\text { Distribution of } \\
\text { elements }\end{array}$ & $\begin{array}{c}\text { Element } \\
\text { Quantity }\end{array}$ & $\begin{array}{c}\text { Flow of heat } \\
\left(\mathbf{W} / \mathbf{m}^{2}\right)\end{array}$ & $\mathbf{N u}$ \\
\hline $41 \times 41$ & 1600 & 3876.92 & 39.08 \\
$81 \times 81$ & 6400 & 3072.95 & 30.97 \\
$121 \times 121$ & 14400 & 2812.9 & 28.35 \\
$161 \times 161$ & 25600 & 2812.6 & 28.35 \\
$321 \times 321$ & 102400 & 2737.5 & 27.59 \\
\hline
\end{tabular}

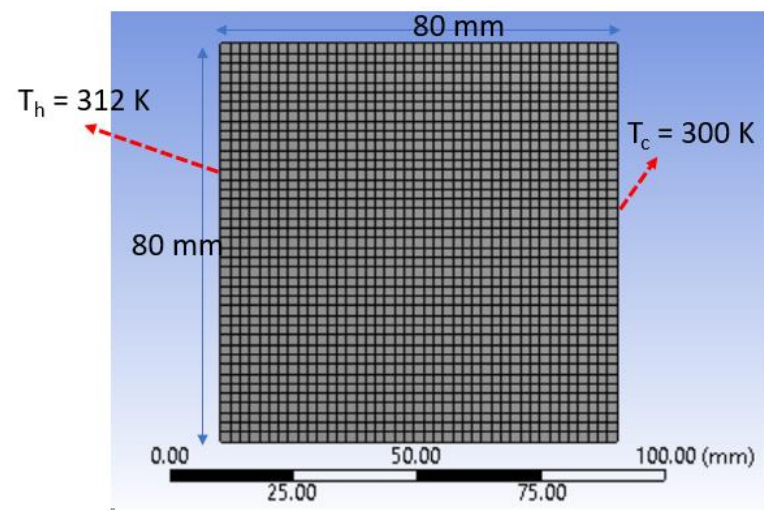

Figure 3. Mesh grid for sensitivity analysis

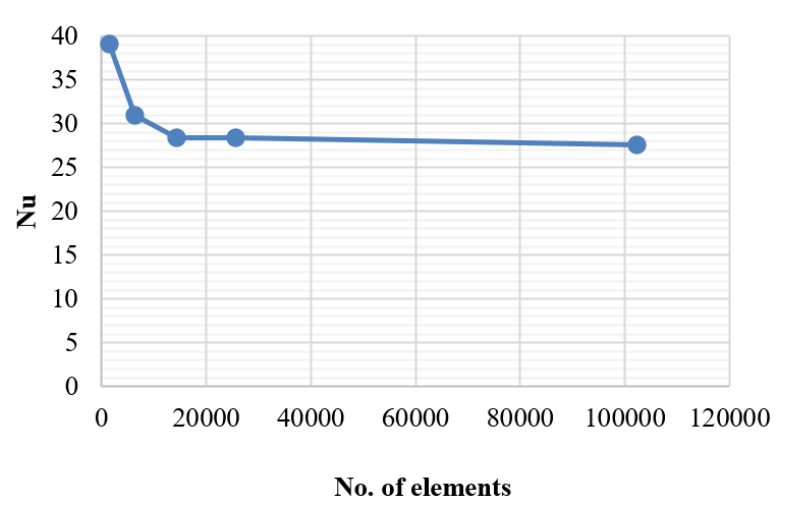

Figure 4. Nusselt number variation with the mesh size 
Table 3. Data validation

\begin{tabular}{cccc}
\hline \%vol of nanoparticle & Nu (from Ho et al. [17]) & Nu (from Sahgir et al. [18]) & Nu (from present analysis) \\
\hline 1 & 33.4 & 33.04695485 & 32.6286731 \\
2 & 32.08 & 32.6144861 & 31.88343706 \\
3 & 30.01 & 32.21165602 & 31.31363385 \\
\hline
\end{tabular}

\section{RESULT ANALYSIS}

Figure 5 (a) and (b) represents the temperature contours of aluminium oxide based water and ethylene glycol nano fluid. The percent volume concentration of $\mathrm{Al}_{2} \mathrm{O}_{3}$ nanoparticles is adjusted to 3 percent in both square cavities, and the hot wall edge is maintained at $324 \mathrm{~K}$. With regard to $\mathrm{Al}_{2} \mathrm{O}_{3}$-water nanofluid and also $\mathrm{Al}_{2} \mathrm{O}_{3}$-EG nanofluids enclosures, the respective RAYLEIGH values are 15.6 (107) and 4.38 (107) (for each). The greater the Rayleigh number, the stronger the flow, which intensifies natural convection. As a result, the isotherms demonstrate that the temperature gradient at the hot and cold walls is more severe in the context of $\mathrm{Al}_{2} \mathrm{O}_{3}$-water nanofluids.

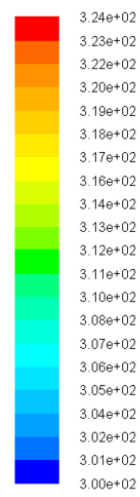

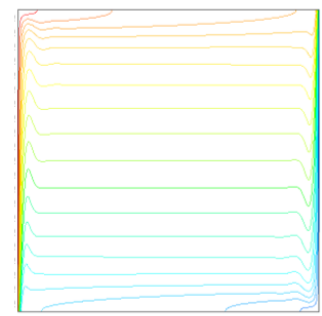

5(a) Aluminium Oxide with
Water nanofluid

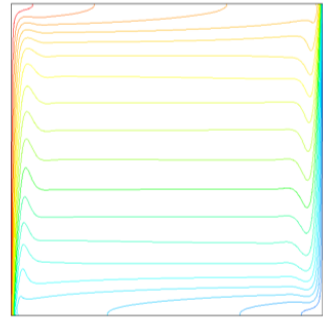

5(b) Aluminium Oxide with Ethylene glycol nanofluid
Figure 5. Comparison of temperature contour for 3\% concentration

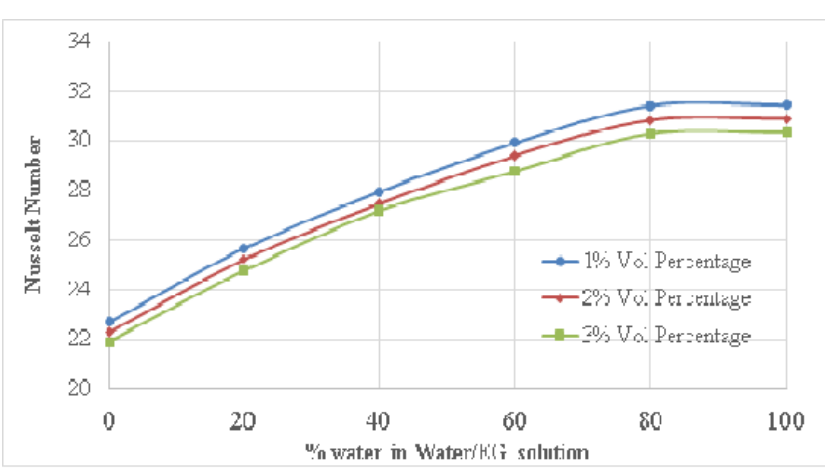

Figure 6. Comparison of Nusselt number for different nanoparticle volume fractions with respect to fraction of water in water/EG solution

Plot of Nusselt number change with base fluid composition from clean EG to water-EG combination and back to pure water is shown in Figure 6. With the hot wall at $312 \mathrm{~K}$ and three different \%vol nanoparticle concentrations, the analysis is completed. When shown in Figure 6, the Nusselt number rises as the baseline fluid composition shifts from EG to water, regardless of the percent vol concentration. Although the rise is almost linear, the figure flattens out when the composition becomes mostly water-based. For an $80 / 20$ water-EG combination and a pure water base fluid, the Nusselt value is almost the same.

The velocity curves shown in Figure 7 are displayed to examine the impact of the hot heated wall on heat transfer rate. A rise in the Rayleigh number correlates with an increase in the flow strength due to the increased temperature of the wall. This increases the amplitude and activity of the velocity, as shown in Figure 7. The increase in Nusselt number driven by an increase in amplitude and activity of velocity is shown in Figure 8.

Figures 9 and 10 show the heat convection ratio of $\mathrm{Al}_{2} \mathrm{O}_{3}$ water nanoparticles and $\mathrm{Al}_{2} \mathrm{O}_{3}$-EG nanocomposites at different nanoparticles concentrations ( $h n f h b f /$ ) to improve the understanding on the impact of nanoparticle volumetric fraction on heat augmentation. The maximum heat enhancement occurs at a value of $=3 \%$ and increases to 4.5 percent.
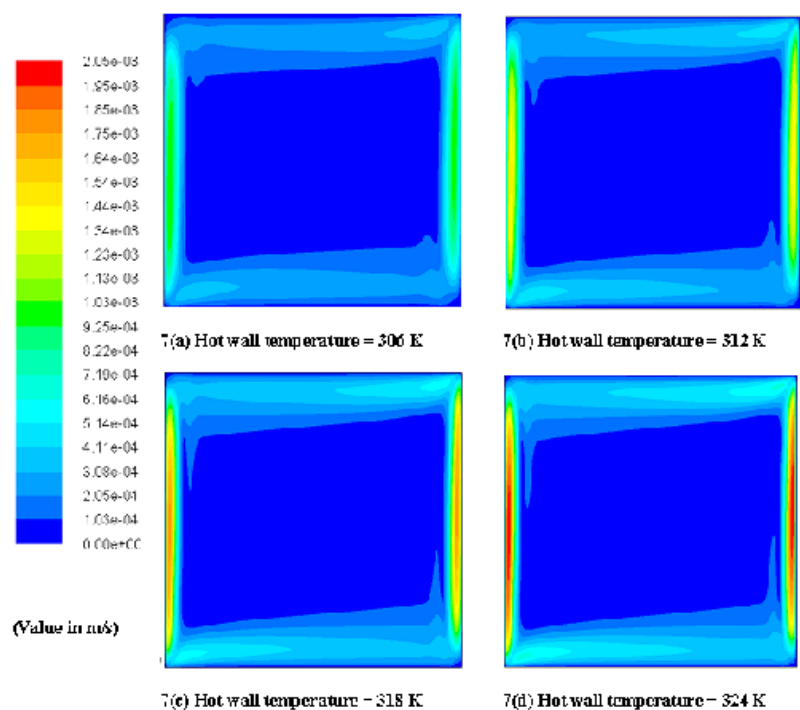

7(b) Hot wall temperature $=312 \mathrm{~K}$

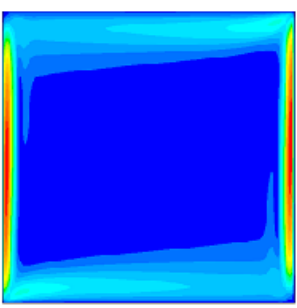

7(d) Hot wall trompcrature $-324 \mathrm{~K}$

Figure 7. Comparison of velocity contour for 0.3 volume fractioned $\mathrm{Al}_{2} \mathrm{O}_{3}$-EG nanofluid (at different wall temperatures)

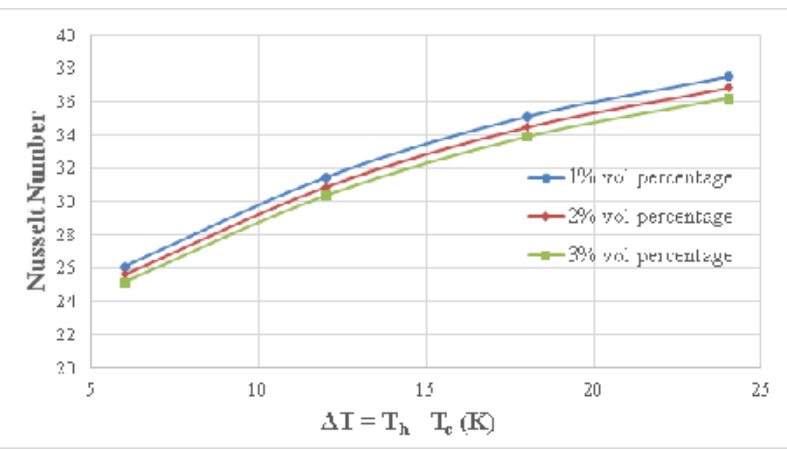

Figure 8. Comparison of Nusselt number vs wall temperature difference (for different nano particle volume fractions) 


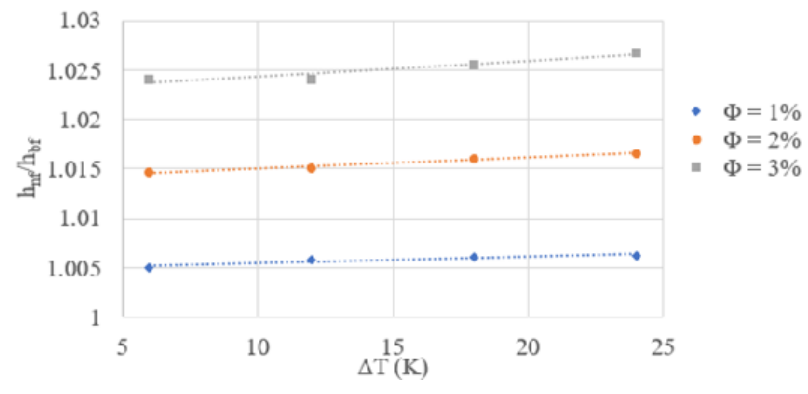

Figure 9. Comparison of heat enhancement ratio of water nanofluid vs temperature difference for different nanoparticles concentration

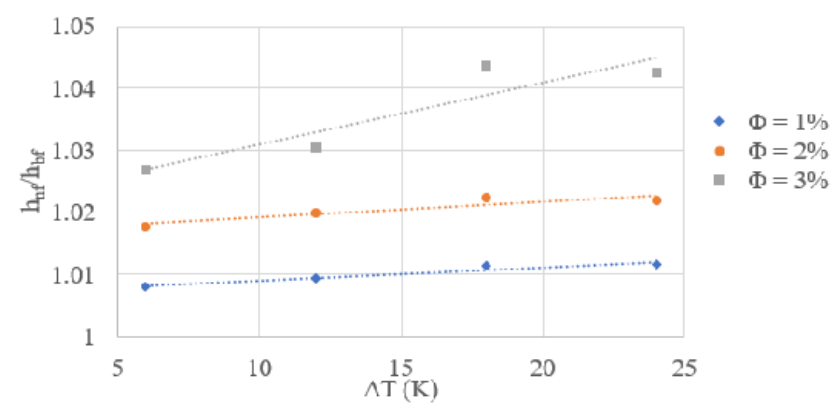

Figure 10. Comparison of heat enhancement ratio of ethylene glycol nanofluid vs temperature difference for different nanoparticles concentration

\section{CONCLUSIONS}

A detailed heat transfers numerical analysis on a square enclosure filled with nano fluids is carried out. There is an 8 $\mathrm{cm}$ square hollow edge. Its horizontal walls are maintained adiabatic meanwhile its vertical walls remain isothermal (having a hot and a cold side) (or insulated). Water, water-EG combination, and EG are tested for Nusselt number change with varying wall temperatures and varying nanoparticle concentrations in $\mathrm{Al}_{2} \mathrm{O}_{3}$ nanoparticle suspensions. The Rayleigh number rises as the wall temperature rises, resulting in more activity and, as a result, better heat transmission. In addition, when the base fluid's composition variations between EG into the water, the rate of heat transmission increases. The ( $h n f h b f /$ ) ratio improves and an improvement of up to 4.5 percent may be obtained with an increase in $\mathrm{Al}_{2} \mathrm{O}_{3}$ nanoparticle percent vol concentration. As a result, the author comes to the conclusion that utilizing nanofluids helps improve heat transmission.

\section{REFERENCES}

[1] Haddad, Z., Oztop, H.F., Abu-Nada, E., Mataoui, A. (2012). A review on natural convective heat transfer of nanofluids. Renewable and Sustainable Energy Reviews, 16(7):

5363-5378 https://doi.org/10.1016/j.rser.2012.04.003

[2] Kleinstreuer, C., Feng, Y. (2011). Experimental and theoretical studies of nanofluid thermal conductivity enhancement: a review. Nanoscale Research Letters, 6(1): 1-13. https://doi.org/10.1186/1556-276X-6-229

[3] Kamyar, A., Saidur, R., Hasanuzzaman, M. (2012). Application of computational fluid dynamics (CFD) for nanofluids. International Journal of Heat and Mass Transfer, 55(15-16): 4104-4115. https://doi.org/10.1016/j.ijheatmasstransfer.2012.03.052

[4] Li, C.H., Peterson, G.P. (2010). Experimental studies of natural convection heat transfer of $\mathrm{Al}_{2} \mathrm{O}_{3} / \mathrm{DI}$ water nanoparticle suspensions (nanofluids). Advances in Mechanical Engineering, 2: 742739. https://doi.org/10.1155\%2F2010\%2F742739

[5] Dagtekin, I., Oztop, H.F. (2001). Natural convection heat transfer by heated partitions within enclosure. International Communications in Heat and Mass Transfer, 28(6): 823-834. https://doi.org/10.1016/S07351933(01)00286-X

[6] Hwang, K.S., Lee, J.H., Jang, S.P. (2007). Buoyancydriven heat transfer of water-based $\mathrm{Al}_{2} \mathrm{O}_{3}$ nanofluids in a rectangular cavity. International Journal of Heat and Mass Transfer, 50(19-20): 4003-4010. https://doi.org/10.1016/j.ijheatmasstransfer.2007.01.037

[7] Putra, N., Roetzel, W., Das, S.K. (2003). Natural convection of nano-fluids. Heat and Mass Transfer, 39(8): 775-784. https://doi.org/10.1007/s00231-002-0382-z

[8] Göktepe, S., Atalık, K., Ertürk, H. (2014). Comparison of single and two-phase models for nanofluid convection at the entrance of a uniformly heated tube. International Journal of Thermal Sciences, 80: 83-92. https://doi.org/10.1016/j.ijthermalsci.2014.01.014

[9] Hajipour, M., Dehkordi, A.M. (2014). Mixed-convection flow of $\mathrm{Al}_{2} \mathrm{O}_{3}-\mathrm{H}_{2} \mathrm{O}$ nanofluid in a channel partially filled with porous metal foam: experimental and numerical study. Experimental Thermal and Fluid Science, 53: 4956. https://doi.org/10.1016/j.expthermflusci.2013.11.002

[10] Qi, C., He, Y., Yan, S., Tian, F., Hu, Y. (2013). Numerical simulation of natural convection in a square enclosure filled with nanofluid using the two-phase Lattice Boltzmann method. Nanoscale Research Letters, 8(1): 1-16. https://doi.org/10.1186/1556-276X-8-56

[11] Nguyen, C.T., Desgranges, F., Galanis, N., Roy, G., Maré, T., Boucher, S., Mintsa, H.A. (2008). Viscosity data for $\mathrm{Al}_{2} \mathrm{O}_{3}$-water nanofluid-hysteresis: Is heat transfer enhancement using nanofluids reliable? International Journal of Thermal Sciences, 47(2): 103111. https://doi.org/10.1016/j.ijthermalsci.2007.01.033

[12] Yazdi, M.E., Nejad, A.K., Dinarvand, S., Tamim, H. (2014). Brownian motion effects on natural convection of alumina-water nanofluid in 2-D enclosure. Heat Transfer-Asian Research, 43(8): 720-733. https://doi.org/10.1002/htj.21121

[13] Buongiorno, J. (2006). Convective transport in nanofluids. Journal of Heat Transfer, 128(3): 240-250. https://doi.org/10.1115/1.2150834

[14] Pak, B.C., Cho, Y.I. (1998). Hydrodynamic and heat transfer study of dispersed fluids with submicron metallic oxide particles. Experimental Heat Transfer an International Journal, 11(2): 151-170. https://doi.org/10.1080/08916159808946559

[15] Ahadi, A., Yousefi, T., Saghir, M. Z. (2013). Double diffusive convection and thermodiffusion of fullerenetoluene nanofluid in a porous cavity. The Canadian Journal of Chemical Engineering, 91(12): 1918-1927. https://doi.org/10.1002/cjce.21801

[16] Khanafer, K., Vafai, K., Lightstone, M. (2003). Buoyancy-driven heat transfer enhancement in a twodimensional enclosure utilizing nanofluids. International 
Journal of Heat and Mass Transfer, 46(19): 3639-3653. https://doi.org/10.1016/S0017-9310(03)00156-X

[17] Ho, C.J., Liu, W.K., Chang, Y.S., Lin, C.C. (2010). Natural convection heat transfer of alumina-water nanofluid in vertical square enclosures: An experimental study. International Journal of Thermal Sciences, 49(8): $1345-1353$. https://doi.org/10.1016/j.ijthermalsci.2010.02.013

[18] Saghir, M.Z., Ahadi, A., Yousefi, T., Farahbakhsh, B. (2016). Two-phase and single phase models of flow of nanofluid in a square cavity: Comparison with experimental results. International Journal of Thermal Sciences, 100 :

372-380. https://doi.org/10.1016/j.ijthermalsci.2015.10.005 